\title{
Somatic IDH1 mutation in a pituitary adenoma of a patient with Maffucci syndrome
}

\author{
*Shuyu Hao, MD, PhD, ${ }^{1}$ Christopher S. Hong, BA, ${ }^{2}$ Jie Feng, MD, PhD, ${ }^{3}$ Chunzhang Yang, PhD, ${ }^{2}$ \\ Prashant Chittiboina, MD, ${ }^{2}$ Junting Zhang, MD, ${ }^{1}$ and Zhengping Zhuang, MD, PhD ${ }^{2}$
}

\begin{abstract}
'Department of Neurological Surgery, Beijing Tiantan Hospital; ${ }^{3 B}$ Beijing Neurosurgical Institute, Capital Medical University, Beijing, China; and ${ }^{2}$ National Institute of Neurological Disorders and Stroke, Surgical Neurology Branch, National Institutes of Health, Bethesda, Maryland
\end{abstract}

\begin{abstract}
Maffucci syndrome is a rare disease characterized by multiple enchondromas and soft-tissue hemangiomas. Additionally, neuroendocrine tumors including pituitary adenomas have been described in these patients. The underlying genetic etiology lies in somatic mosaicism of mutations in isocitrate dehydrogenase 1 (IDH1) or isocitrate dehydrogenase 2 (IDH2). This report describes a patient with Maffucci syndrome who presented with intracranial tumors of the skull base and suprasellar region. The patient underwent resection of both intracranial tumors, revealing histopathological diagnoses of chondrosarcoma and pituitary adenoma. DNA sequencing of the tumors was performed to identify common IDH1/2 mutations. Clinical, radiological, and biochemical assessments were performed. Genotypic studies used standard Sanger sequencing in conjunction with a target-specific peptide nucleic acid to detect IDH1 mutations in tumor tissues. DNA sequencing demonstrated identical IDH1 mutations (c.394C > T) in both tumors.

To the authors' knowledge, this report provides the first genetic evidence for the inclusion of pituitary adenomas among tumors characterizing Maffucci syndrome. In patients who are newly diagnosed with Maffucci syndrome, it is appropriate to monitor for development of pituitary pathology and neuroendocrine dysfunction.

http://thejns.org/doi/abs/10.3171/2015.4.JNS15191
\end{abstract}

KEY WORDS pituitary adenoma; isocitrate dehydrogenase; somatic mosaicism; Maffucci syndrome; oncology

$\mathrm{M}$ AFFUCCI syndrome and Ollier disease (OMIM 166000, ICD-10 Q78.4) are noninheritable conditions that are characterized by multiple enchondroma formation. ${ }^{18}$ Unlike Ollier disease, patients with Maffucci syndrome also form soft-tissue hemangiomas. Patients typically present during the 1 st decade of life with asymmetrical skeletal deformities and limb-length discrepancies, and may require surgery. Up to $40 \%$ of patients undergo malignant transformation of enchondromas into chondrosarcomas.$^{30}$ Recently, it was shown that individuals with Maffucci syndrome and Ollier disease harbor somatic mosaicism of mutations in isocitrate dehydrogenase 1 (IDH1) or isocitrate dehydrogenase $2(I D H 2){ }^{1}$

Maffucci syndrome was originally characterized as enchondromatosis with hemangioma. However, additional tumors have been reported in these patients, including lymphangiomas, pancreatic adenocarcinomas, biliary ad- enocarcinomas, osteosarcomas, and mesenchymal ovarian tumors. ${ }^{2,13,17,29}$ Additionally, intracranial tumors including astrocytomas, olfactory neuroblastomas, malignant chordomas, spindle cell hemangioendotheliomas, and pituitary adenomas have been described. ${ }^{3,22,26}$ However, the only genetic evidence to demonstrate causality in these associations has been limited to an IDHI-mutated ovarian fibroma and an IDH2-mutated anaplastic astrocytoma in Ollier disease and Maffucci syndrome, respectively. ${ }^{13,22}$

We describe a patient with Maffucci syndrome who presented with 2 intracranial tumors: a jugular foramen chondrosarcoma and a pituitary adenoma. Both tumors exhibited identical IDHI mutations and represent the first genetic evidence of pituitary adenoma formation in Maffucci syndrome. Therefore, pituitary adenomas should be included among tumors in Maffucci syndrome that arise from somatic IDHI/2 mutations.

ABBREVIATIONS ACTH = adrenocorticotropic hormone; FSH = follicle-stimulating hormone; GH = growth hormone; IDH1 = isocitrate dehydrogenase $1 ;$ IDH2 = isocitrate dehydrogenase 2; LH = luteinizing hormone; $M E N 1$ = multiple endocrine neoplasia 1; PCR = polymerase chain reaction; $P N A=$ peptide nucleic acid; PRL = prolactin; $R E T$ = rearranged during transfection; $S D H=$ succinate dehydrogenase; $\mathrm{TSH}=$ thyroid-stimulating hormone.

SUBMITTED January 26, 2015. ACCEPTED April 23, 2015.

INCLUDE WHEN CITING Published online October 16, 2015; DOI: 10.3171/2015.4.JNS15191.

* Dr. Hao and Mr. Hong contributed equally to this work. 


\section{Methods}

\section{Study Oversight}

This study was approved by the institutional review board of Beijing Tiantan Hospital of Capital Medical University (Beijing, China). The index patient provided written informed consent.

\section{Immunohistochemistry}

Routine H \& E staining was performed on formalinfixed tissue specimens to confirm histopathological diagnosis. Immunohistochemical staining was performed using the Bond automatic stainer and Bond ready-touse antisynaptophysin antibody (both from Leica). Images were obtained at 200× magnification using a Nikon Eclipse Ci microscope with a Nikon DS-Fi2 camera.

\section{DNA Extraction}

DNA was extracted from formalin-fixed, paraffin-embedded tumor tissues using the QIAamp DNA FFPE Tissue Kit (Qiagen).

\section{Polymerase Chain Reaction Conditions}

Standard polymerase chain reaction (PCR) experiments contained 200-500 ng genomic DNA, $25 \mu l$ Taq $2 \times$ Master Mix (New England BioLabs), and $0.25 \mu \mathrm{l}$ each of forward and reverse primers $(100 \mu \mathrm{M})$ in a final volume of $50 \mu \mathrm{l}$. The PCR conditions were as follows: denaturation at $94^{\circ} \mathrm{C}$ for 15 minutes; followed by 40 cycles of $94^{\circ} \mathrm{C}$ for 30 seconds (denaturation), $55^{\circ} \mathrm{C}$ for 30 seconds (primer annealing), and $68^{\circ} \mathrm{C}$ for 60 seconds (extension), with a final extension step at $68^{\circ} \mathrm{C}$ for 5 minutes.

\section{Peptide Nucleic Acid Design and PCR Conditions}

The peptide nucleic acid (PNA) designed to detect wildtype $I D H I$ was produced by PNA Bio. The sequence of the PNA was CATCATAGGTCGTCATGCTT-Lys-Lys. The 2 terminal lysine residues were added for improved solubility. The PCR experiments contained 200-500 ng genomic DNA, $25 \mu \mathrm{l}$ Taq $2 \times$ Master Mix (New England BioLabs), $0.25 \mu \mathrm{l}$ each of forward and reverse primers $(100 \mu \mathrm{M})$, and $0.5 \mu \mathrm{l}$ PNA $(100 \mathrm{nM})$ in a final volume of $50 \mu \mathrm{l}$. The PCR conditions were as follows: denaturation at $94^{\circ} \mathrm{C}$ for 15 minutes; followed by 40 cycles of $94^{\circ} \mathrm{C}$ for 30 seconds (denaturation), $68^{\circ} \mathrm{C}$ for 60 seconds (PNA hybridization), $55^{\circ} \mathrm{C}$ for 30 seconds (primer annealing), and $72^{\circ} \mathrm{C}$ for 60 seconds (extension), with a final extension step at $72^{\circ} \mathrm{C}$ for 7 minutes.

\section{Detection of R132 Mutation With Nested PCR and PNA Application}

PCR amplification to introduce a site-directed mutation was initially performed, using $100 \mathrm{nM}$ PNA as described above (forward primer ACCAACGACCAAGTCACCAA, reverse primer GTGTTGAGATGGACGCCTATT). PCR products were purified using QIAquick PCR columns (Qiagen). Subsequently, PCR amplification was repeated with the PNA, using nested primers (forward primer TGTGGAAATCACCAAATGGCAC, reverse primer TT GCTTAATGGGTGTAGATACCA). After purification, PCR products were analyzed by gel electrophoresis and subjected to Sanger sequencing for $I D H I$ mutations, using the nested forward primer. The GenBank (National Center for Biotechnology Information) accession number for IDHI is NM_005896.2.

\section{Case Report}

\section{History and Examination}

A 28-year-old man presented with a 3-year history of voice hoarseness and dysphagia, and a 6-month history of left-sided blurred vision. His medical history was significant for development of multiple palpable nodular masses of the left hand beginning at 7 years of age (Fig. 1A), later accompanied by formation of subcutaneous blue, soft, nontender masses, diagnosed as hemangiomas on physical examination (Fig. 1A, inset). Radiographs of the left hand showed skeletal phalangeal malformation with calcific nodules and multiple enchondromas (Fig. 1B). Chest CT demonstrated enchondromas of the bilateral ribs and scapulae (Fig. 1C). Technetium-99m methylene diphosphonate whole-body bone scintigraphy revealed foci of intense tracer uptake, involving the right humerus, right ulna, right femur, right fibula, right tibia, left humerus, left radius, left hand, left femur, left fibula, and left tibia (Fig. 1D). Based on these findings, the patient was diagnosed with Maffucci syndrome.

Neurological examination revealed left-sided deficits in hearing and gag reflex, bilateral temporal hemianopia, and decreased visual acuity (left eye 20/30; right eye 20/50). Brain MRI demonstrated 2 heterogeneously enhancing lesions, 1 in the left jugular foramen (Fig. 2A and B) and the other in the suprasellar region (Fig. 2C and D). The latter was suggestive of a pituitary macroadenoma. Serum prolactin (PRL), insulin-like growth factor-I, growth hormone (GH), cortisol, adrenocorticotropic hormone $(\mathrm{ACTH})$, thyroid hormone, thyroid-stimulating hormone (TSH), luteinizing hormone (LH), and folliclestimulating hormone (FSH) were normal. A diagnosis of Maffucci syndrome associated with a nonfunctional pituitary adenoma was proposed.

\section{Operation and Postoperative Course}

A subtotal resection of the contrast-enhancing left jugular foramen lesion through a retrosigmoid approach was performed, resulting in significant improvement of the patient's dysphagia and auditory acuity. Histopathological review of the surgical specimen diagnosed a chondrosarcoma. Ten months after the first operation, the patient underwent gross-total resection of the suprasellar lesion via a subfrontal approach, revealing a diagnosis of pituitary adenoma. His postoperative recovery was uneventful other than transient polyuria. At the 2-year follow-up, the patient's voice hoarseness and visual acuity were significantly improved.

\section{Pathological Examination and DNA Sequencing}

Pathological examination of the jugular foramen specimen revealed a Grade II chondrosarcoma, characterized by moderate cellularity with occasional mitotic figures, cellular atypia, and increased muco-myxoid degeneration of chondroid matrix (Fig. 2E). Histopathological review of the pituitary adenoma demonstrated a highly cellular 

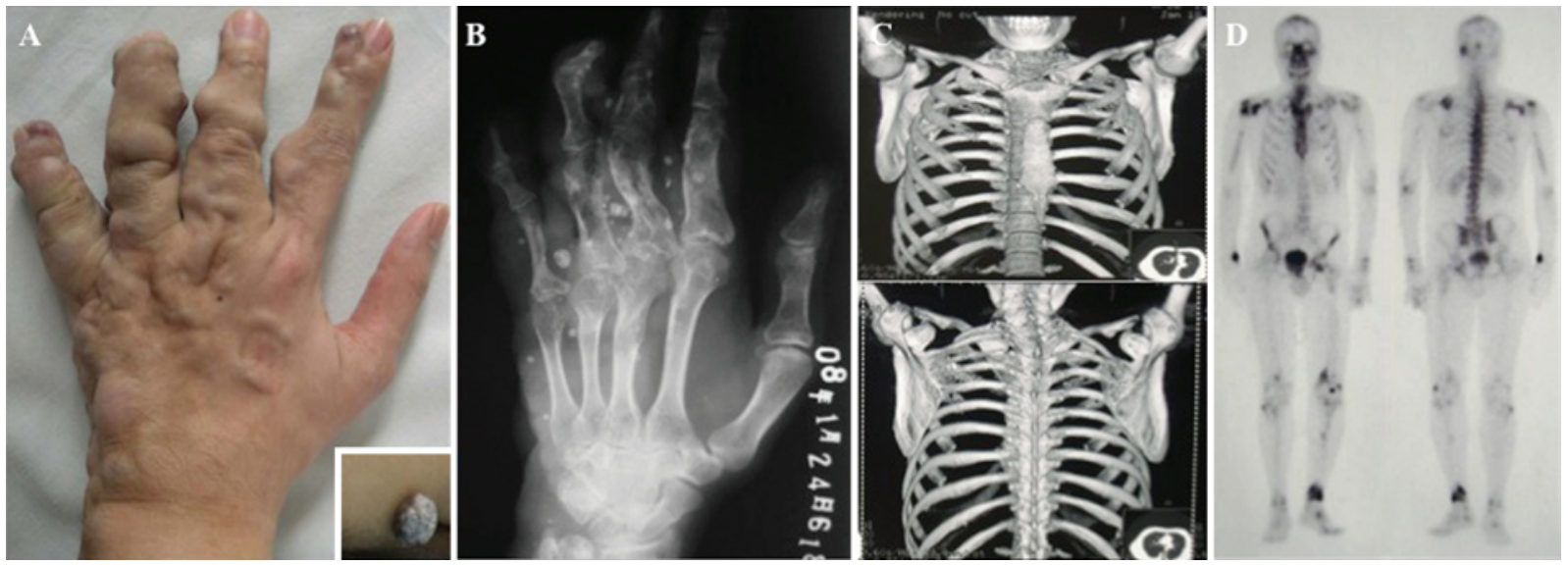

FIG. 1. Clinical presentation of index patient. A photograph of the index patient's left hand is shown (A). Numerous palpable nodules were evident, which had been present since childhood. Multiple hemangiomas spread throughout his body were found, including his right buttock (inset). A radiograph of the left hand showed calcific nodules and lytic lesions of the phalanges, characteristic of enchondromas (B). 3D anterior (upper panel) and posterior (lower panel) reconstruction of a chest CT showed additional osseous lytic lesions (C). Whole-body bone scintigraphy revealed multiple areas of increased radiotracer uptake, suggestive of enchondromatosis (D). Figure is available in color online only.

tumor with prominent monomorphism and loss of the normal reticulin meshwork (Fig. 2F). Immunohistochemical staining for synaptophysin confirmed this tumor to be of neuroendocrine origin (Fig. 2F, inset). Additional immunohistochemical investigation was negative for GH, PRL, LH, FSH, TSH, and ACTH (not shown).

Sanger sequencing of DNA from the pituitary adenoma revealed a c.394C > T mutation, a substitution of arginine at codon 132 with cysteine (R132C) (Fig. 3 center). To confirm these results, we performed repeat Sanger sequencing on significantly limited, remaining tissue, using nested PCR technique and a custom-designed PNA against the wild-type IDHI sequence (Fig. 3 lower). Use of PNA has been demonstrated to be an effective PCR
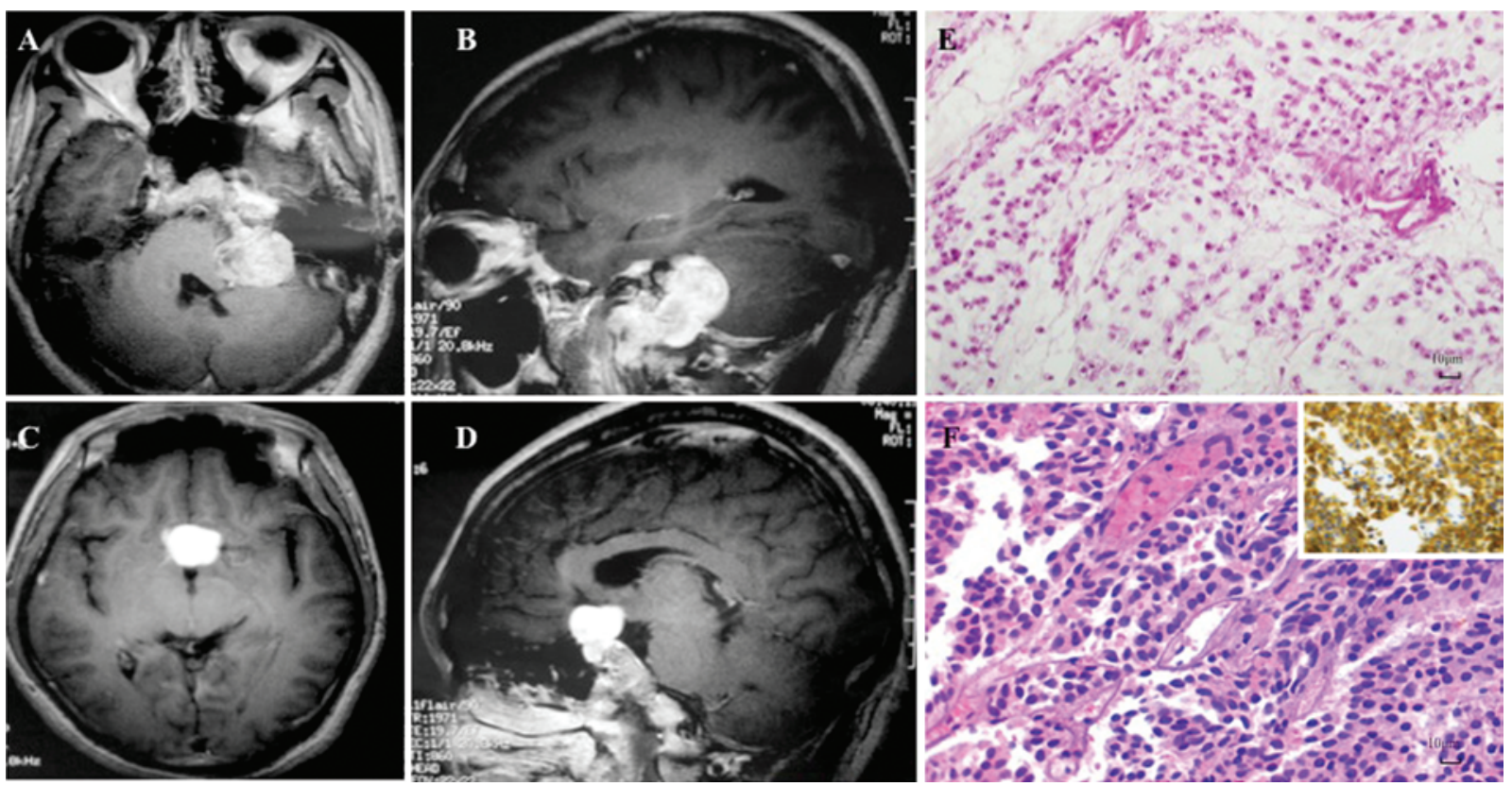

FIG. 2. Radiographic and histological tumor characteristics. Axial (A) and sagittal (B) sections of a T1-weighted MRI study obtained after contrast administration demonstrated a heterogeneously enhancing lesion encasing the left jugular foramen of the skull base. Axial (C) and sagittal (D) T1-weighted MRI studies obtained after contrast administration showed a strongly enhancing suprasellar mass. A representative image of the $\mathrm{H} \& \mathrm{E}$-stained sample (original magnification $\times 200$ ), excised from the jugular foramen, exhibited increased cellular atypia amid a degenerative muco-myxoid chondroid matrix, suggestive of a Grade II chondrosarcoma (E). An H \& E-stained photomicrograph (original magnification $\times 200$ ) of tissue from the suprasellar mass showed monomorphic cellularity and disorganized reticulin meshwork (F). There was prominent positive staining for the neuroendocrine marker, synaptophysin, confirming neuroendocrine origin and diagnostic of pituitary adenoma (inset). Figure is available in color online only. 


\section{Chondrosarcoma}

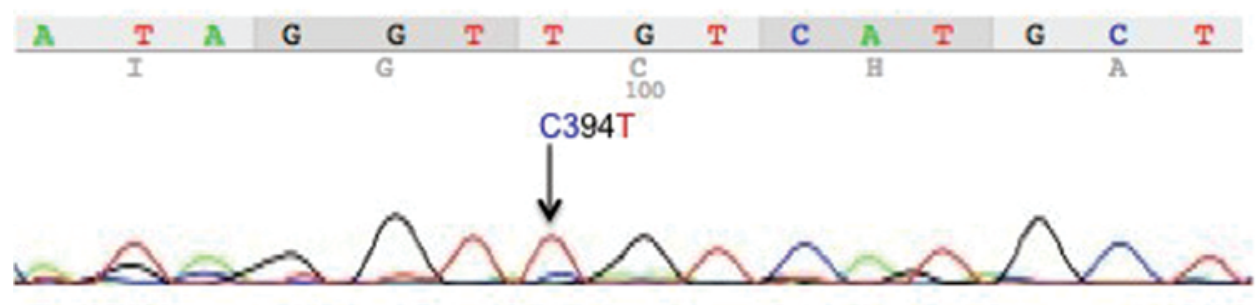

Pituitary Adenoma
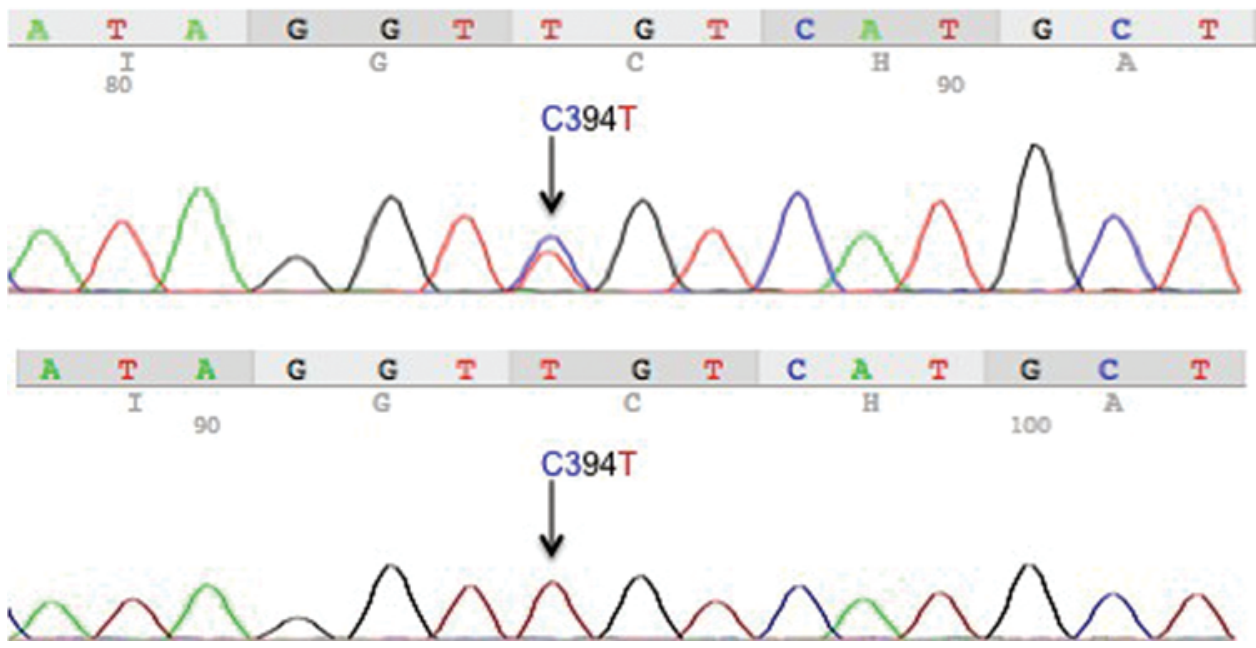

FIG. 3. DNA sequencing of tumor IDH1. Sanger sequencing of DNA extracted from the pituitary adenoma revealed a c. 394C $>T$ (R132C) mutation of IDH1 (center). Repeat sequencing was performed on DNA derived from remaining paraffin-embedded tissue, using PNA and nested PCR technique, which confirmed previous results (lower). Using the same methodology of PNA and nested PCR, the same c.394C > T mutation was found in DNA from the chondrosarcoma tissue (upper). Figure is available in color online only.

clamp of wild-type sequences in samples where mutated cells are sparse. ${ }^{6}$ Similarly, chondrosarcoma tissue was very limited but using the same techniques, a c.394C > T (R132C) mutation was detected (Fig. 3 upper).

\section{Discussion}

Although pituitary adenomas in patients with Maffucci syndrome have been previously described, ${ }^{27}$ none established causality of pituitary adenoma in Maffucci syndrome through analysis of $I D H 1 / 2$ mutations. Our report of a pituitary adenoma sharing an identical IDHI mutation with a chondrosarcoma in a patient with Maffucci syndrome supports the inclusion of pituitary adenomas among tumors characterizing Maffucci syndrome. Further investigations may reveal $I D H 1 / 2$ mutations in other tumor types reported to arise in patients with Maffucci syndrome.

Excluding the current study, 11 cases of pituitary adenoma in patients with Maffucci syndrome have been described and are shown in Table 1. ${ }^{5,8,10,11,14,15,19,20,23,27,28}$ Among these, the majority (6/11) presented solely with visual field deficits, as did our patient. Further, none exhibited symptoms or evidence from immunohistochemical staining and/ or laboratory testing of hormonal abnormalities, indicative of a predominance of nonfunctional pituitary adenomas in this patient population. All patients except for 2 underwent resection, 1 of whom was diagnosed postmortem. ${ }^{5}$ The other patient was treated with radiation only and was without recurrence at the 3 -year follow-up. ${ }^{19}$ There were 2 more cases of tumor recurrence within 3 years after surgical removal of the pituitary adenoma. ${ }^{10,28}$ Further, similar to the patient described by Miki et al., ${ }^{20}$ there was little evidence of sellar enlargement upon review of imaging from our patient, which, although atypical for a pituitary adenoma, does not exclude its diagnosis. ${ }^{25}$ Taken together, the clinical course of our patient is consistent with these previous studies, i.e., he presented solely with visual field deficits secondary to a nonfunctional pituitary adenoma and responded well to surgical treatment alone.

To our knowledge, the current case represents the first case of an IDHI-mutated pituitary adenoma. Balss et al. analyzed 23 samples of sporadic nonfunctional pituitary adenomas and failed to detect $I D H I$ mutations, using direct DNA-sequencing techniques. ${ }^{4}$ Similarly, Ikota et al. performed immunohistochemical staining for $I D H 1 \mathrm{mu}-$ tations in 42 pituitary adenoma samples, of which 2 exhibited $10 \%-30 \%$ positive immunoreactivity. ${ }^{9}$ However, positive staining in these samples was confined to the cytoplasm. Because of this, the authors stated these find- 
TABLE 1. Previously published cases of pituitary adenomas in patients with Maffucci syndrome

\begin{tabular}{lll}
\hline \multicolumn{1}{c}{ Authors \& Year } & \multicolumn{1}{c}{ Clinical Presentation } & Features of Histological Subtype \\
\hline Kuzma \& King, 1948 & Asymptomatic & Not performed \\
\hline Baradnay et al., 1960 & Incidental finding postmortem & Chromophobic staining \\
\hline Jingu et al., 1973 & Visual field defects & Chromophobic staining \\
\hline Schnall \& Genuth, 1976 & Visual field defects & Chromophobic staining \\
\hline Marymont et al., 1987 & Incidental finding & Not performed \\
\hline Miki et al., 1987 & Visual field defects & Chromophobic staining \\
\hline Howie \& Davidson, 1988 & Visual field defects & Basophilic staining \\
\hline Kitamura et al., 2006 & Cluster headaches & Normal endocrine laboratory results \\
\hline Ruivo \& Antunes, 2009 & Visual field deficits & Normal endocrine laboratory results \\
\hline Imai et al., 2012 & Visual field deficits & Not specified \\
\hline Ono et al., 2012 & Not specified & Not specified \\
\hline
\end{tabular}

ings should be considered negative, given the absence of concomitant nuclear staining, which is required for immunohistochemical diagnosis of IDHI mutations.

Maffucci syndrome was originally theorized as a condition of mesodermal dysplasia..$^{18}$ However, our study and Moriya et al. ${ }^{22}$ question this theory because pituitary adenomas and astrocytomas arise from neuroectodermal tissues. Our finding of the same IDHI mutation in the chondrosarcoma (mesodermal origin) and pituitary adenoma (neuroectodermal origin) suggests IDH1/2 mutations are early postzygotic events in Maffucci syndrome, occurring prior to gastrulation. ${ }^{1,22}$ It is unclear which cell types are affected and harbor tumorigenic potential in Maffucci syndrome. Other endocrine tumors have been described in Maffucci syndrome, including thyroid adenoma, parathyroid adenoma, pheochromocytoma, and paraganglioma. ${ }^{7,12,16,20,24}$ Further, endocrine tumor syndromes have been attributed to mutations in cellular metabolism genes, including succinate dehydrogenase $(S D H)$, hypoxia-inducible factor 2-alpha $(H I F 2 A)$, multiple endocrine neoplasia 1 (MEN1), rearranged during transfection (RET), and Von Hippel-Lindau (VHL). IDH1/2 mutations similarly alter metabolic pathways via mutant enzymatic production of the onco-metabolite, D-2-hydroxyglutarate, promoting development of low-grade gliomas and hematopoietic malignancies. ${ }^{21}$ As this report suggests, $I D H 1 / 2$ mutations in Maffucci syndrome may affect cells beyond mesenchymal lineage, including neuroectodermal cells that may form tumors. IDHI/2 sequencing of more neuroendocrine tumors from patients with Maffucci syndrome will be required to answer this question.

In summary, we provide sufficient genetic evidence for the inclusion of pituitary adenomas among tumors that arise from IDHI mutation mosaicism in Maffucci syndrome. Because IDHI/2 mutations in Maffucci syndrome predispose cells to, rather than incite, tumorigenesis, it is yet to be seen whether $I D H 1$ and $I D H 2$ represent cancersusceptibility genes, similar to $S D H, M E N 1$, and RET.

\section{Acknowledgments}

We thank Dr. Guilin Li (Beijing Neurosurgical Institute, Capital Medical University, Beijing, China) and Dr. Abhik RayChaudhury (National Institute of Neurological Disorders and
Stroke, NIH, Bethesda, MD) for their assistance in histopathological analysis. We also thank Drs. Liwei Zhang, Zhen Wu, and Sumin Geng (Beijing Tiantan Hospital, Capital Medical University, Beijing, China) for their editing of the case presentation. This work was supported by the Intramural Research Program of the National Institute of Neurological Disorders and Stroke at the NIH as well as the National Natural Science Foundation of China (No. 81341059) and Beijing Nova program (No. 2012033).

\section{References}

1. Amary MF, Damato S, Halai D, Eskandarpour M, Berisha F, Bonar F, et al: Ollier disease and Maffucci syndrome are caused by somatic mosaic mutations of IDH1 and IDH2. Nat Genet 43:1262-1265, 2011

2. Auyeung J, Mohanty K, Tayton K: Maffucci lymphangioma syndrome: an unusual variant of Ollier's disease, a case report and a review of the literature. J Pediatr Orthop B 12:147-150, 2003

3. Balcer LJ, Galetta SL, Cornblath WT, Liu GT: Neuroophthalmologic manifestations of Maffucci's syndrome and Ollier's disease. J Neuroophthalmol 19:62-66, 1999

4. Balss J, Meyer J, Mueller W, Korshunov A, Hartmann C, von Deimling A: Analysis of the IDH1 codon 132 mutation in brain tumors. Acta Neuropathol 116:597-602, 2008

5. Baradnay G, Hoffmann J, Okros J: [Dyschondroplasia and hemangiomatosis (Maffuci's syndrome)]. Orv Hetil 101:1753-1755, 1960 [Hungarian]

6. Chiou CC, Luo JD, Chen TL: Single-tube reaction using peptide nucleic acid as both PCR clamp and sensor probe for the detection of rare mutations. Nat Protoc 1:2604-2612, 2006

7. Counts AL, Widlak RA: Generalized idiopathic external root resorption. J Clin Orthod 27:511-513, 1993

8. Howie FM, Davidson JK: Case report 492: Chondrosarcoma of right ischium developing in a patient with Maffucci syndrome. Skeletal Radiol 17:368-374, 1988

9. Ikota H, Nobusawa S, Tanaka Y, Yokoo H, Nakazato Y: High-throughput immunohistochemical profiling of primary brain tumors and non-neoplastic systemic organs with a specific antibody against the mutant isocitrate dehydrogenase 1 R132H protein. Brain Tumor Pathol 28:107-114, 2011

10. Imai E, Kawamata T, Yamamoto K, Mochidome M, Kawamata M: [Anesthetic management of a patient with Maffucci syndrome for removal of a pituitary adenoma.] Masui 61:538-541, 2012 (Jpn)

11. Jingu K, Katayama J, Takahashi M, Chin C: [Case of Maffucci's syndrome.] Rinsho Hoshasen 18:281-286, 1973 (Jpn)

12. Juul SE, Kinsella MG, Wight TN, Hodson WA: Alterations 
in nonhuman primate (M. nemestrina) lung proteoglycans during normal development and acute hyaline membrane disease. Am J Respir Cell Mol Biol 8:299-310, 1993

13. Kenny SL, Patel K, Humphries A, Davis M, Flanagan AM, McCluggage WG: Ovarian cellular fibroma harbouring an isocitrate dehydrogenase $1(1 \mathrm{DH} 1)$ mutation in a patient with Ollier disease: evidence for a causal relationship. Histopathology 62:667-670, 2013

14. Kitamura E, Imai N, Konisi T, Suzuki Y, Serizawa M, Okabe T: [Cluster like headache in a patient with the Maffucci's syndrome.] No To Shinkei 58:514-517, 2006 (Jpn)

15. Kuzma JF, King JM: Dyschondroplasia with hemangiomatosis, Maffucci's syndrome, and teratoid tumor of the ovary. Arch Pathol (Chic) 46:74-82, 1948

16. Lamovec J, Frković-Grazio S, Bracko M: Nonsporadic cases and unusual morphological features in pheochromocytoma and paraganglioma. Arch Pathol Lab Med 122:63-68, 1998

17. Lewis RJ, Ketcham AS: Maffucci's syndrome: functional and neoplastic significance. Case report and review of the literature. J Bone Joint Surg Am 55:1465-1479, 1973

18. Loewinger RJ, Lichtenstein JR, Dodson WE, Eisen AZ: Maffucci's syndrome: amesenchymal dysplasia and multiple tumour syndrome. Br J Dermatol 96:317-322, 1977

19. Marymont JV, Fisher RF, Emde GE, Limbird TJ: Maffucci's syndrome complicated by carcinoma of the breast, pituitary adenoma, and mediastinal hemangioma. South Med J 80:1429-1431, 1987

20. Miki K, Kawamoto K, Kawamura Y, Matsumura H, Asada Y, Hamada A: A rare case of Maffucci's syndrome combined with tuberculum sellae enchondroma, pituitary adenoma and thyroid adenoma. Acta Neurochir (Wien) 87:79-85, 1987

21. Molenaar RJ, Radivoyevitch T, Maciejewski JP, van Noorden CJ, Bleeker FE: The driver and passenger effects of isocitrate dehydrogenase 1 and 2 mutations in oncogenesis and survival prolongation. Biochim Biophys Acta 1846:326-341, 2014

22. Moriya K, Kaneko MK, Liu X, Hosaka M, Fujishima F, Sakuma J, et al: IDH2 and TP53 mutations are correlated with gliomagenesis in a patient with Maffucci syndrome. Cancer Sci 105:359-362, 2014

23. Ono S, Tanizaki H, Fujisawa A, Tanioka M, Miyachi Y: Maffucci syndrome complicated with meningioma and pituitary adenoma. Eur J Dermatol 22:130-131, 2012

24. Puech-Bret N, Bret J, Bennet A, Huyghe E, Mazerolles C, Zabraniecki L, et al: Maffucci syndrome and adrenal cortex tumor. Joint Bone Spine 76:556-558, 2009
25. Ramakrishnan VR, Suh JD, Lee JY, O’Malley BW Jr, Grady MS, Palmer JN: Sphenoid sinus anatomy and suprasellar extension of pituitary tumors. J Neurosurg 119:669-674, 2013

26. Ranger A, Szymczak A: Do intracranial neoplasms differ in Ollier disease and Maffucci syndrome? An in-depth analysis of the literature. Neurosurgery 65:1106-1115, 2009

27. Ruivo J, Antunes JL: Maffucci syndrome associated with a pituitary adenoma and a probable brainstem tumor. J Neurosurg 110:363-368, 2009

28. Schnall AM, Genuth SM: Multiple endocrine adenomas in a patient with the Maffucci syndrome. Am J Med 61:952-956, 1976

29. Schwartz HS, Zimmerman NB, Simon MA, Wroble RR, Millar EA, Bonfiglio M: The malignant potential of enchondromatosis. J Bone Joint Surg Am 69:269-274, 1987

30. Verdegaal SH, Bovée JV, Pansuriya TC, Grimer RJ, Ozger H, Jutte PC, et al: Incidence, predictive factors, and prognosis of chondrosarcoma in patients with Ollier disease and Maffucci syndrome: an international multicenter study of 161 patients. Oncologist 16:1771-1779, 2011

\section{Disclosure}

The authors report no conflict of interest concerning the materials or methods used in this study or the findings specified in this paper.

\section{Author Contributions}

Conception and design: Zhuang, Hao, Zhang. Acquisition of data: Zhuang, Hao, Hong, Feng, Chittiboina, Zhang. Analysis and interpretation of data: all authors. Drafting the article: all authors. Critically revising the article: all authors. Reviewed submitted version of manuscript: Zhuang, Hao, Hong, Feng, Zhang. Approved the final version of the manuscript on behalf of all authors: Zhuang. Administrative/technical/material support: Hao, Feng. Study supervision: Zhuang, Zhang.

\section{Correspondence}

Zhengping Zhuang, Surgical Neurology Branch, National Institute of Neurological Disorders and Stroke, National Institutes of Health, 10 Center Dr., Rm. 3D05, Bethesda, MD 20892. email: zhuangp@ninds.nih.gov. 